\title{
Using Journal Review Articles to Increase the Dissemination of Keynote and Symposia Lectures at International Medical Congresses
}

\author{
D. M. Wood • P. I. Dargan
}

Published online: 14 July 2012

(C) American College of Medical Toxicology 2012

There are an increasing number of congresses and conferences that are of relevance to medical (clinical) toxicologists each year around the world. In addition to attending for an individual's own educational and developmental needs, there are increasing requests to deliver lectures and symposia at these congresses and conferences. Clearly, it is impractical, unaffordable and inappropriate to spend the majority of the year travelling around the world and therefore not possible to attend all of these conferences. Whilst many conferences publish the original scientific presentations at the meeting in abstract form, it is more unusual for keynote lectures and lectures within symposia to be published alongside these abstracts. Therefore, the content of these lectures is often not available to the wider audience unable to attend the meeting(s). In this Editorial we describe our previous and ongoing work with the British Journal of Clinical Pharmacology and the Journal of Medical Toxicology to try and promote the use of reviews/mini-reviews by the presenters of lectures/symposia at conferences to disseminate the information in their lectures to a wider audience.

In 2008 we organised a 'bench to bedside' symposium on behalf of the Clinical Section of the British Pharmacological Society (BPS) entitled 'Cocaine induced cardiac arrhythmias

\author{
D. M. Wood • P. I. Dargan \\ Guy's and St Thomas' NHS Foundation Trust \\ and King's Health Partners, \\ London, UK \\ D. M. Wood • P. I. Dargan \\ King's College London, \\ London, UK \\ D. M. Wood $(\bowtie)$ \\ Medical Toxicology Office, Guy's Hospital, \\ 2nd Floor Bermondsey Wing, Great Maze Pond, \\ London SE1 9RT, UK \\ e-mail: David.Wood@gstt.nhs.uk
}

- from ion channel to clinical treatment'. This was delivered at the Winter Meeting of the BPS in 2008. This involved world-recognised speakers from both within the UK and from North America, invited for their specific expertise relevant to this symposium. One of our thoughts as the organisers of the symposium was whether there was the possibility of wider dissemination of the content of this symposium to a wider audience than attended the Winter Meeting, to maximise the impact of bringing together the world experts in this 'bench to bedside' symposium. The symposium started with discussion of the epidemiology of cocaine use and toxicity, followed by overview of the impact of cocaine on sodium and other myocardial ion channels and finished with a pragmatic clinical overview of the presentation and management of cocaine-related arrhythmias. Following discussion with the British Journal of Clinical Pharmacology, the journal of the Clinical Section of the BPS, it was agreed, prior to the symposium, that they would publish a series of review articles from the symposium in a single future issue of the journal [1-3]. These articles underwent the usual peer-review process prior to publication, and the series of review articles were published in the print version of the journal approximately 1 year after the symposium. Whilst it is not possible to determine the impact of publishing these lectures as a complete series of review articles, we feel that it allows the reader to follow the content of the symposium in a single issue of the journal and therefore benefit in the same way as those who attended the symposium from the 'bench to bedside' approach to the topic.

The American College of Medical Toxicology (ACMT) was invited to deliver a symposium at the 10th Asia Pacific Association of Medical Toxicology (APAMT) congress in Penang, Malaysia, in November 2011. Given the significant interest in the issues related to the use and toxicity of classical recreational drugs and novel psychoactive substances, it was agreed with the conference scientific committee 
that a symposium addressing this topic would be appropriate and of interest to the congress attendees. The symposium was entitled 'Recreational Drugs in the Asia Pacific Region'. Although this was an ACMT symposium, it was felt important that this involved not only speakers from Europe and North America, but also local experts from the Asia Pacific region. Similar to the symposium we organised at the Winter Meeting of the British Pharmacological Society in 2008, we felt that it would be advantageous to publish a series of mini-reviews based on the lectures of the symposium. As this was an ACMT symposium, the Journal of Medical Toxicology gave provisional approval for publication of the series of mini-reviews prior to the meeting, subject to usual peer review of the articles after submission. The symposium gave an overview of the epidemiology of recreational drug use in the Asia Pacific region together with an update on the toxicity of drugs commonly used (e.g. opioids, methamphetamine, ketamine and dextromethorphan) and emerging trends. The symposium was very well received by those who attended the APAMT congress, and in this issue of the Journal of Medical Toxicology, the series of mini-reviews from the symposium is published [4-7]. We hope that the wider readership of the Journal of Medical Toxicology will find these articles of interest. Other journals also publish reviews based on congress keynote/symposia lectures, with some publishing selected reviews from congresses (e.g. Clinical Toxicology [8]) and others publishing a symposium report (e.g. Journal of the Royal College of Physicians of Edinburgh [9]).

Through this process, we have learnt a number of key issues to ensure that the series of reviews fit together as a series and are published in a single issue of a journal. In particular, it requires encouragement from a lead individual or individuals to ensure that the articles are not only written and submitted on time, but also written in a way that will engage with the journal audience. It is also important to ensure that the peer-review process is as timely as possible. We are pleased that, building on the publication of this minireview series from the 2011 APAMT congress, the Journal of Medical Toxicology has again given provisional approval for publication of a series of mini-reviews based on the ACMT symposium at the forthcoming 2012 APAMT congress in Hong Kong entitled 'An update on the management of paracetamol (acetaminophen) poisoning with a focus on the Asia Pacific region'. We feel that this has the potential to become an annual initiative based on the work that the ACMT undertakes with sister toxicology societies around the world, and hope that this is supported by not only the Editorial Board of the Journal of Medical Toxicology, but also the wider readership.

\section{References}

1. O'Leary ME, Hancox JC (2010) Role of voltage-gated sodium, potassium and calcium channels in the development of cocaineassociated arrhythmias. Br J Clin Pharmacol 69:427-442

2. Hoffman RS (2010) Treatment of patients with cocaine-induced arrhythmias: bringing the bench to the bedside. Br J Clin Pharmacol 69:448-457

3. Wood DM, Dargan PI (2010) Putting cocaine use and cocaineassociated cardiac arrhythmias into epidemiological and clinical perspective. Br J Clin Pharmacol 69:443-447

4. Wood DM, Dargan PI (2012) Understanding how data triangulation identifies acute toxicity of novel psychoactive drugs. J Med Toxicol. doi:10.1007/s13181-012-0241-3

5. Dargan PI, Wood DM (2012) Recreational drug use in the Asia Pacific Region: improvement in our understanding of the problem through the UNODC Programmes. J Med Toxicol. doi:10.1007/ s13181-012-0240-4

6. Chomchai C, Manaboriboon B (2012) Stimulant methamphetamine and dextromethorphan use among Thai adolescents: implications for health of women and children. J Med Toxicol. doi:10.1007/s13181-012-0228-0

7. Yiu-Cheung C (2012) Acute and chronic toxicity pattern in ketamine abusers in Hong Kong. J Med Toxicol. doi:10.1007/s13181-012-0229-z

8. Gibbons S (2012) 'Legal highs' - novel and emerging psychoactive drugs: a chemical overview for the toxicologist. Clin Toxicol (Phila) $50: 15-24$

9. Isles C, Robertson S, Almond A, Donaldson K, Clark D (2011) The challenges of renal replacement therapy and renal palliative care in the elderly. J R Coll Physician Edinb 41:238-243 